\title{
The Portuguese DISABKIDS Asthma Module: A global index of asthma- specific quality of life for children and adolescents
}

Neuza Silva • Carlos Carona $•$ Carla Crespo • Monika Bullinger • Maria Cristina Canavarro

\begin{abstract}
Introduction. The KIDSCREEN and DISABKIDS questionnaires constitute a modular system for assessing the health-related quality of life (HrQoL) of children/adolescents. Objective: This study was aimed at examining the factorial structure of the Portuguese patient- and parent-reported versions of the DISABKIDS-Asthma Module (AsM) and its invariance across age groups and informants, as well as to examine their reliability and construct validity. Method. The sample included 140 children/adolescents aged 8-18 years, who were diagnosed with asthma, and one of their parents. Both family members assessed HrQoL at the generic (KIDSCREEN-10), chronicgeneric (DISABKIDS-I2) and asthma-specific (DISABKIDS-AsM) levels. Asthma severity was classified by physicians using Global Initiative for Asthma (GINA) guidelines. Results. Confirmatory factor analysis attested the factorial validity of the correlated two-factor model of the DISABKIDS-AsM, but the low average variance extracted by each factor (Impact and Worry) suggested that a one-factor structure would better fit the Portuguese data. The one-factor model had an acceptable fit $\left(\chi^{2} / \mathrm{df}=1.97\right.$; comparative fit index $=0.94$; root mean square error of approximation $=0.08$ ) and was invariant between age groups (children vs. adolescents) and informants (patient-reports vs. parent-reports). The resulting global index of asthma-specific HrQoL presented good reliability and convergent validity with the generic and chronic-generic measures. The DISABKIDS instruments also detected significant differences in HrQoL regarding asthma severity groups. Conclusion. The DISABKIDS-AsM may be regarded as a specific onedimensional questionnaire, which, besides suiting pediatric patients in different developmental stages and enabling reliable proxy-reports, is sensitive to asthma clinical characteristics and is cross-culturally comparable, thus representing a valuable tool for assessing asthma-specific $\mathrm{HrQoL}$ as a primary health outcome in clinical practice and research contexts.
\end{abstract}

\section{Keywords}

Asthma-specific assessment • Children and adolescents • DISABKIDS questionnaires • Healthrelated quality of life $\bullet$ Patient-reported and parent-reported outcomes $\bullet$ Psychometrics 


\section{Introduction}

Asthma is a chronic inflammatory disease of the airways with a high prevalence worldwide, particularly among pediatric patients (Pearce et al., 2007). In Portugal, its prevalence is nearly $9 \%$ in children and $14 \%$ in adolescents (Pinto, 20l I). Episodic exacerbations of asthma symptoms can be life threatening and are a major cause of hospitalizations among pediatric patients (Global Initiative for Asthma Program [GINA], 2008). Moreover, the dependence on medication, sleep disturbances, daytime fatigue, physical limitations, school absenteeism and academic underachievement may impair the health-related quality of life (HrQoL) of children and adolescents, particularly when asthma is poorly controlled (Dean et al., 20I0; Schmier et al., 2007). Some comparative studies with healthy controls have reported decreased generic HrQoL in pediatric asthma patients (Grootenhuis, Koopman, Verrips, Vogels, \& Last, 2007; Upton et al., 2005; Varni, Limbers, \& Burwinkle, 2007); however, other studies have failed to detect significant differences (Chan, Mangione-Smith, Burwinkle, Rosen, \& Varni, 2005; Moreira et al., 2013). When comparing children/adolescents with asthma to children/adolescents with other medical conditions, no significant impairments have been found in HrQoL total scores (Anderson, Czosek, Knilans, \& Marino, 2012; Bullinger, Schmidt, Petersen, \& Ravens-Sieberer, 2006; Moreira et al., 20I3), but lower scores in the physical domain have been reported for pediatric asthma patients (Austin, Smith, Risinger, \& McNelis, 1994; Varni et al., 2007).

These inconsistent findings may be the result of methodological constraints, namely, the use of broad-scope instruments that may neglect the most specific HrQoL domains affected by asthma. Therefore, a multilevel assessment of pediatric HrQoL, including generic and diseasespecific measures, is recommended (World Health Organization [WHO], 1993). The European KIDSCREEN and DISABKIDS projects provide a set of age-appropriate and cross-culturally comparable questionnaires in a three-level modular system for assessing pediatric HrQoL (Baars et al., 2005; Bullinger et al., 2006; Ravens-Sieberer et al., 2007). While the generic measures are suitable for all children and adolescents and allow comparisons between healthy and clinical populations, the chronic-generic and disease-specific measures ensure sensitivity to diseaserelated impairments and healthcare needs and allow the detection of subtle but clinically relevant differences or changes in the health status of patients (Guyatt, 1995; Wiebe, Guyatt, Weaver, Matijevic, \& Sidwell, 2003).

This article reports the results from the field validation study of a specific instrument to assess the HrQoL in Portuguese children and adolescents with asthma. Following standard procedures for cross-cultural instrument adaptation (Schmidt \& Bullinger, 2003), the patient- and parent-reported versions of the DISABKIDS-Asthma Module (AsM) (The DISABKIDS Group Europe, 2006) were previously translated into Portuguese language and internationally 
harmonized to ensure the conceptual equivalence of items. Semantic validation and pilot testing were also performed to verify the comprehensibility, relevance and adequacy of items and response scales (Silva, Carona, Crespo, \& Canavarro, 201I). The main goal of this study was to ascertain the psychometric properties of the Portuguese patient- and parent-reported versions of the DISABKIDS-AsM questionnaires. Specifically, we aimed to examine the following: (I) the original correlated two-factor model of the DISABKIDS-AsM, as well as an alternative one-factor model; (2) the invariance of the measurement model across age groups (children aged 8-12 years vs. adolescents aged 13-18 years) and informants (patient-reports vs. parent-reports); (3) the reliability of the questionnaires; (4) their construct validity (convergent validity with the generic and chronic-generic instruments and known-groups validity with regard to asthma severity levels as assessed by physicians), as well as their correlations with asthma symptoms as perceived by children/adolescents and their parents; and (5) the child-parent agreement on ratings of asthmaspecific HrQoL.

\section{Method}

\section{Participants and procedure}

The participants were dyads of children/adolescents diagnosed with asthma and one of their parents. Data collection occurred between June $20 \mathrm{II}$ and February 2012 in the outpatient services of three Portuguese public hospitals, upon the study's approval by the respective Ethics Committees and/or Direction Boards, and in agreement with the following inclusion criteria: (I) age between 8 and 18 years; (2) diagnosis of asthma, established by a physician according to the International Classification of Diseases-10, for at least one year; (3) requiring regular or emergency medication intake; (4) absence of comorbidity with other health conditions; and (5) be accompanied by a parent currently assuming the role of primary family caregiver (i.e. the parent self-identified as mainly responsible for the child's asthma management). The children and adolescents who attended medical routine appointments in the period of data collection were screened by their physicians based on their medical files, and those who met the aforementioned criteria were invited to participate in the study (non-probabilistic convenience sampling method).

Following the World Medical Association Declaration of Helsinki's guidelines (World Medical Association [WMA], 2008) and national legal requirements, detailed information about the study aims and procedures was provided to all participants, and informed consent was obtained from parents and adolescents older than 13 years, and informal assent was obtained from younger children. The children/adolescents and parents who agreed to participate $(n=144$ dyads) completed the questionnaires independently, in a room designated for research purposes 
in the health institution they attended. A research assistant was available to provide support whenever necessary and to prevent the exchange of information between children and parents.

Measures

Pediatric HrQoL was assessed by children/adolescents and their parents using the Portuguese patient- and parent-reported versions of the generic KIDSCREEN-I0 index (RavensSieberer et al., 2010), the DISABKIDS-12 chronic-generic module (The DISABKIDS Group Europe, 2006) and the DISABKIDS asthma-specific module (The DISABKIDS Group Europe, 2006). The KIDSCREEN-10 index comprises 10 items assessing general subjective health and well-being (e.g., "Have you felt fit and well?"/ "Has your child felt fit and well?"), and the DISABKIDS- 12 includes 10 items measuring the impact of chronic health conditions (e.g., "Does your condition get you down?"| "Does your child's condition get him/her down?") and two items measuring the impact of treatments on patients' lives (e.g., "Does taking medication bother you?"/ "Does taking medication bother your child?"). The DISABKIDS-AsM comprises II items focused on the experience of limitations and symptoms (Impact, six items; e.g., "Do you feel that you get easily exhausted?"| "Does your child feel that he/she gets easily exhausted?") and on fears and worries about having asthma (Worry, five items; e.g., "Are you worried that you might have an asthma attack?"/ "Is your child worried that he/she might have an asthma attack?"). The DISABKIDS-AsM questionnaires also include three questions assessing the participants' perceptions of asthma symptoms. The three questionnaires were answered using a five-point Likert scale, ranging from I (never/not at all) to 5 (always/extremely). Standardized scores (0-100) were calculated, with higher scores indicating better HrQoL.

Parents also completed a socio-demographic datasheet soliciting for their age, gender, educational level and occupational status, as well as their children's age, gender and clinical information (e.g., age at the time of asthma diagnosis and use of medication). Following the Global Initiative for Asthma guidelines (GINA, 2008), the clinical severity of asthma was classified by physicians into four categories: intermittent, mild persistent, moderate persistent and severe persistent.

\section{Statistical analyses}

The statistical analyses were performed with the Statistical Package for the Social Sciences, v.20 (SPSS Inc., Chicago, IL). Except for clinical and socio-demographic variables, missing data, which were random and less than $5 \%$ of the values, were handled by replacement with the individual mean score for each scale. Descriptive statistics were calculated for socio- 
demographic and clinical variables.

The factor structure of the Portuguese patient- and parent-reported versions of the DISABKIDS-AsM was examined with confirmatory factor analyses (CFA) using the Analysis of Moment Structures, v.20 (AMOS Development Corporation, Meadville, PA). The models' goodness-of-fit was assessed based on the maximum-likelihood $\chi^{2}$ statistic, the comparative fit index (CFI), the root mean square error of approximation (RMSEA) and the standardized root mean squared residual (SRMR). A model was considered to have a good fit when CFI $\geq .95$, RMSEA $\leq .06$ and SRMR $\leq .08$, and was considered to have an acceptable fit when CFI $\geq .90$ and RMSEA $\leq .10$ (Browne \& Cudeck, 1993; Hu \& Bentler, 1999). The factorial validity of the DISABKIDS-AsM questionnaires was evaluated based on the significance and strength of factor loadings. The measurement invariance of the model across age groups (children 8-12 years vs. adolescents 13-18 years) and informants (patient-reports vs. parent-reports) was addressed at a strong level by performing multi-group analyses comparing the unconstrained model with a model in which factor loadings (metric invariance) and factor loading and item intercepts (scalar invariance) were fixed equally across groups (Dimitrov, 20I0).

The reliability of the DISABKIDS-AsM questionnaires was assessed by using Cronbach's alpha coefficients and composite reliability (CR) values, calculated from the squared sum of standardized factor loading divided by the squared sum of standardized factor loading and error variance terms. Good construct reliability was established if CR was higher than .70 (Hair, Black, Babin, \& Anderson, 2010). Construct validity was examined by calculating Pearson correlation coefficients between the DISABKIDS-AsM questionnaires and the generic and chronic-generic HrQoL measures (convergent validity), and by comparing HrQoL across groups expected to differ in this health construct (known-groups validity) (DeVellis, 20I2). Multivariate analyses of covariance (MANCOVA) were performed to compare the generic, chronic-generic and asthmaspecific HrQoL between asthma severity groups (intermittent asthma vs. persistent asthma), while controlling for children's age and gender by including them as covariates. When multivariate effects were significant, univariate analyses were performed to examine which levels of HrQoL were significantly different between groups. In addition, correlation coefficients between HrQoL and asthma symptoms as perceived by the children/adolescents and by parents were examined. Agreement between patient- and parent-reports of pediatric generic, chronicgeneric and asthma-specific HrQoL was tested at the individual and group levels (Sneeuw, Sprangers, \& Aaronson, 2002) by using, respectively, intraclass correlation coefficients (ICC) (two-way mixed model, absolute agreement, 95\% confidence interval) and MANCOVA for repeated measures (entering the informant as the within-subject factor and the children's age and gender as covariates). 


\section{Results}

Sample characteristics

Four cases were excluded due to missing values in a ratio greater than $5 \%$ of the data. The final sample included 140 dyads of children/adolescents diagnosed with asthma and one of their parents. The socio-demographic and clinical characteristics of the sample are presented in Table I. Due to the low frequency of participants at each asthma severity level, this variable was dichotomized into intermittent $(n=83,59.3 \%)$ and persistent asthma $(n=57,40.7 \%)$ for the subsequent analyses.

Table I | Socio-demographic and clinical characteristics of the sample

\begin{tabular}{|c|c|c|}
\hline & $\begin{array}{l}\text { Pediatric patients } \\
(n=\mid 40)\end{array}$ & $\begin{array}{l}\text { Parents } \\
(n=140)\end{array}$ \\
\hline \multicolumn{3}{|l|}{ Socio-demographic characteristics } \\
\hline Age (in years), $M(S D)$ & $12.18(2.70)$ & $42.04(7.11)$ \\
\hline \multicolumn{3}{|l|}{ Age group, $n(\%)$} \\
\hline Children (8- 12 years) & $79(56.4 \%)$ & \\
\hline Adolescents (13-18 years) & $61(43.6 \%)$ & \\
\hline \multicolumn{3}{|l|}{ Gender, $n(\%)$} \\
\hline Male & $89(63.6 \%)$ & 27 (19.3\%) \\
\hline Female & $51(36.4 \%)$ & II 3 (80.7\%) \\
\hline \multicolumn{3}{|l|}{ Socio-economic level ${ }^{\mathrm{a}}, \mathrm{n}(\%)$} \\
\hline Low & & $83(59.3 \%)$ \\
\hline Medium & & $52(37.1 \%)$ \\
\hline High & & $5(3.6 \%)$ \\
\hline \multicolumn{3}{|l|}{ Clinical characteristics } \\
\hline \multicolumn{3}{|l|}{ Asthma severity ${ }^{\mathrm{b}}, \mathrm{n}(\%)$} \\
\hline Intermittent & $83(59.3 \%)$ & \\
\hline Mild persistent & $33(23.6 \%)$ & \\
\hline Moderate persistent & $20(14.3 \%)$ & \\
\hline Severe persistent & $4 \quad(2.9 \%)$ & \\
\hline Disease length (in years), $M(S D)$ & $7.66(4.17)$ & \\
\hline
\end{tabular}

${ }^{a}$ The socio-economic level was determined using a classification system for the Portuguese context based on parents' job and educational level (Simões, 1994). ${ }^{b}$ Asthma severity as assessed by physicians according to the GINA guidelines (2008).

\section{Confirmatory factor analyses}

The original correlated two-factor model of the DISABKIDS-AsM questionnaire had an unacceptable fit to the patient-reported data, with $\chi^{2}(43)=138.72, p \leq .001 ; \mathrm{CFI}=.84$; RMSEA $=$ 
.13 ; and SRMR $=.08$. The inspection of modification indices suggested that items I, 3 and 4 might be correlated. Although these three items were hypothesized to load on different domains, all three were related to physical activity; therefore, their measurement errors were allowed to correlate. The modified model had an acceptable fit, with $\chi^{2}(40)=76.22, p \leq .00 \mathrm{I}$; $\mathrm{CFI}=.94$; RMSEA $=.08$; and SRMR $=.07$, which was significantly better than the original model, with $\Delta \chi^{2}(3)$ $=62.50, p \leq .00 \mathrm{I}$. All factor loadings were statistically significant and, except for item 2 , were above the threshold of .50. However, the average variance extracted (AVE) by each factor, as calculated from the sum of squared standardized factor loadings divided by the sum of squared standardized factor loadings and error terms (Fornell \& Larcker, I98I) (AVE $=.40$ for Impact and $.4 \mathrm{I}$ for Worry), was lower than the squared correlation between the two factors $\left(r^{2}=.88\right)$, indicating that they did not measure different constructs.

A one-factor model, in which all items loaded on a global index of asthma-specific HrQoL, was also tested. The one-factor model (Figure I) had an acceptable fit, $\chi^{2}(41)=80.57, p \leq$ $.00 \mathrm{I} ; \mathrm{CFI}=.94 ; \mathrm{RMSEA}=.08$; and SRMR $=.07$. Although the chi-square difference test between the modified correlated two-factor model and the one-factor model was statistically significant, $\Delta \chi^{2}(1)=4.35, p=.037$, indicating a better fit for the two-factor model, the remaining goodnessof-fit indexes were nearly identical. The similarities on goodness-of-fit indexes, as well as the limitations of the two-factor model, namely the low AVE by each factor and the correlations between items which were hypothesized to load on different domains, suggested that the onefactor model would better fit the Portuguese patient-reported data. Therefore, the one-factor model, hereinafter referred to as asthma-specific HrQoL index, was adopted for the subsequent analyses.

The multi-group analysis by age group confirmed that the one-factor model was valid for both children and adolescents, with $\Delta \chi^{2}(11)=15.41, p=.165$ (metric invariance) and $\Delta \chi^{2}(11)=$ $7.89, p=.723$ (scalar invariance).

The one-factor model was also tested for parent-reported data, given our aim of validating an equivalent model for both versions of the instrument (Figure I). The model had a nearly acceptable fit, with $\chi^{2}(40)=112.1 \mathrm{I}, p \leq .00 \mathrm{I}$; CFI $=.89$; RMSEA $=. \mathrm{II}$; and SRMR $=.09$. In addition, the multi-group analysis confirmed that factor loadings and item means did not differ significantly between informants (patient-reported data vs. parent-reported data), with $\Delta \chi^{2}($ II) $=$ $13.94, p=.236$ (metric invariance) and $\Delta \chi^{2}(11)=15.68, p=.154$ (scalar invariance). 


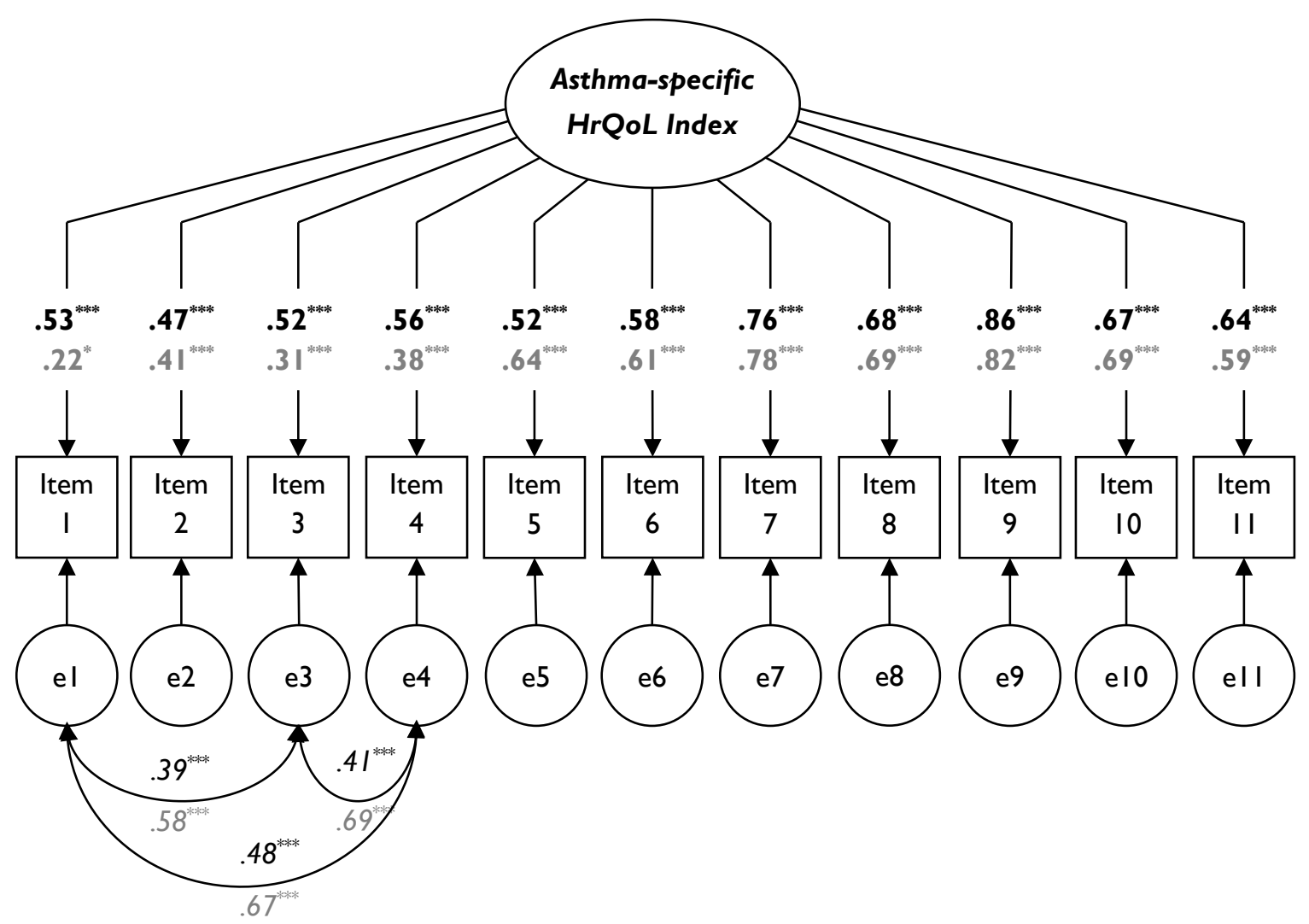

Figure I | One-factor model for patient- and parent-reported versions of the DISABKIDS-AsM questionnaire

Note. Black bold figures represent standardized regression weights of factor loadings for the patient-reported version; gray bold figures represent standardized regression weights of factor loadings for the parent-reported version; black italicized figures represent Pearson correlation coefficients for the patient-reported-version; gray italicized figures represent Pearson correlation coefficients for the parent-reported version. ${ }^{* * * *} p \leq .001 ;{ }^{* *} p \leq .01 ;{ }^{*} p \leq .05$.

\section{Reliability}

The Cronbach's alpha coefficients indicated good internal consistency for the patientreported $(\alpha=.88)$ and parent-reported $(\alpha=.86)$ global index of asthma-specific HrQoL. In addition, CR values calculated from the factor loadings of the II items of the DISABKIDS-AsM questionnaires ( .87 for patient- and .84 for parent-reports) were higher than the recommended threshold of .70 (Hair et al., 20I0).

Adequate internal consistency was also found for the generic and chronic-generic HrQoL measures, with Cronbach's alpha values of .80 (patient-reports) and .77 (parent-reports) for the KIDSCREEN-I0 instrument; and $\alpha=.65$ (patient-reports) and $\alpha=.78$ (parent-reports) for the DISABKIDS- 2 chronic-generic module. 


\section{Construct validity}

The global index of asthma-specific HrQoL was moderately correlated with the generic HrQoL and strongly correlated with the chronic-generic HrQoL, supporting the convergent validity of the DISABKIDS-AsM (Table 2). In addition, patient-reported asthma-specific HrQoL was negatively correlated with children/adolescents' perceptions of asthma symptoms, and parent-reported asthma-specific HrQoL was negatively correlated with parents' perceptions of asthma symptoms (Table 2).

Table 2 | Inter-correlation matrix of patient- and parent-reported HrQoL and asthma symptoms

\begin{tabular}{|c|c|c|c|c|c|c|}
\hline \multirow[t]{3}{*}{ Variablel Measure } & \multirow[t]{3}{*}{ Informant } & \multicolumn{5}{|c|}{ Pearson correlation coefficients } \\
\hline & & \multirow[b]{2}{*}{ I } & \multirow[b]{2}{*}{2} & \multicolumn{3}{|c|}{ Asthma symptoms } \\
\hline & & & & Recency $^{\mathrm{a}}$ & Frequency $^{\mathrm{b}}$ & Severity ${ }^{c}$ \\
\hline \multirow{2}{*}{$\begin{array}{l}\text { I. Generic HrQoL } \\
\text { (KIDSCREEN-I0) }\end{array}$} & Patient & - & - & -.16 & -.13 & -.11 \\
\hline & Parent & - & - & .05 & -.03 & $-.17^{*}$ \\
\hline 2. Chronic-generic HrQoL & Patient & $.6 I^{* * *}$ & - & -.11 & -.08 & -.12 \\
\hline (DISABKIDS-I2) & Parent & $.52^{* * *}$ & - & -.09 & $-.19^{*}$ & $-.30^{* * *}$ \\
\hline 3. Asthma-specific HrQoL & Patient & $.39^{* * *}$ & $.68^{* * * *}$ & -.06 & -.10 & $-.27^{* *}$ \\
\hline (DISABKIDS-AsM) & Parent & $.36^{* * *}$ & $.66^{* * *}$ & $-.17^{*}$ & $-.28^{* *}$ & $-.39^{* * *}$ \\
\hline
\end{tabular}

a Time since last asthma attack, as assessed by pediatric patients and by parents ("When was the last time you/your child had an asthma attack?"). ${ }^{b}$ Frequency of asthma attacks during the last year, as assessed by pediatric patients and by parents ("How many asthma attacks did you/your child have during the last year?"). 'Asthma severity during the last year, as assessed by pediatric patients and by parents ("How severe was your/your child's asthma during the last year?").

${ }^{* * *} p \leq .001 ;{ }^{* *} p \leq .01 ;{ }^{*} p \leq .05$, two-tailed.

A significant multivariate effect of asthma severity levels, as assessed by physicians, was found for both patient- and parent-reports, with Wilks' Lambda $=.92, F_{(3,134)}=3.81, p=.012, \eta_{\mathrm{p}}^{2}$ $=.08$ and Wilks' Lambda $=.89, F_{(3,134)}=5.58, p=.00 \mathrm{I}, \eta_{\mathrm{p}}{ }^{2}=.1 \mathrm{I}$, respectively. The univariate effects (Table 3) showed that children/adolescents with persistent asthma had lower chronicgeneric and asthma-specific HrQoL than patients with intermittent asthma, attesting the knowngroups validity of both generic and asthma-specific modules of the DISABKIDS instruments.

Child-parent agreement

At the individual level, the examination of the ICC indicated poor to moderate levels of agreement between patient- and parent-reports of pediatric HrQoL (Table 4). 
Table 3 | Univariate analyses of covariance of HrQoL between asthma severity levels

\begin{tabular}{|c|c|c|c|c|c|c|}
\hline VariablelMeasure & Informant & Asthma se & ity levels ${ }^{a}$ & & & \\
\hline & & Intermittent & Persistent & & & \\
\hline & & $M(S D)$ & $M(S D)$ & $F_{(1,136)}$ & $p$ & $\eta_{p}^{2}$ \\
\hline Generic HrQoL & Patient & $81.60(13.38)$ & 79.30 (14.89) & 0.96 & .328 & .01 \\
\hline (KIDSCREEN-I0) & Parent & 74.73 (14.99) & $75.00(13.35)$ & 0.06 & .811 & .00 \\
\hline Chronic-generic HrQoL & Patient & 83.18 (1I.7I) & $77.19(14.63)$ & 9.91 & .002 & .07 \\
\hline (DISABKIDS-I2) & Parent & $81.75(12.58)$ & 75.55 (15.17) & 9.79 & .002 & .07 \\
\hline Asthma-specific HrQoL & Patient & $67.42(20.17)$ & $62.56(19.31)$ & 3.49 & .064 & .03 \\
\hline (DISABKIDS-AsM) & Parent & 64.46 (15.99) & $61.40(18.18)$ & 1.66 & .200 & .01 \\
\hline
\end{tabular}

${ }^{a}$ Dichotomized asthma severity levels as assessed by physicians, according to the GINA guidelines (2008).

At the group level, the MANCOVA for repeated measures showed no significant multivariate differences between informants, Wilks' Lambda $=.99, F_{(3,135)}=0.55, p=.651$ (univariate effects are presented in Table 4). In addition, no significant multivariate effects of the interaction between informant and children's age, Wilks' Lambda $=.99, F_{(3,135)}=0.12, p=.949$, or gender, Wilks' Lambda $=.95, F_{(3,135)}=2.17, p=.094$, were found.

Table 4 | Agreement between patient- and parent-reports of generic, chronic-generic and asthma-specific HrQoL

\begin{tabular}{|c|c|c|c|c|c|c|}
\hline Variable/Measure & Informant & $\overline{M(S D)}$ & $F_{(1,137)}$ & $\bar{p}$ & $\eta_{p}^{2}$ & $\mathrm{ICC}^{\mathrm{a}}$ \\
\hline $\begin{array}{l}\text { Generic HrQoL } \\
\text { (KIDSCREEN-I0) }\end{array}$ & $\begin{array}{l}\text { Patient } \\
\text { Parent }\end{array}$ & $\begin{array}{l}80.66(14.01) \\
74.84(14.30)\end{array}$ & 0.68 & 0.410 & 0.01 & $0.35^{* * * *}$ \\
\hline $\begin{array}{l}\text { Chronic-generic HrQoL } \\
\text { (DISABKIDS- I 2) }\end{array}$ & $\begin{array}{l}\text { Patient } \\
\text { Parent }\end{array}$ & $\begin{array}{l}80.74(13.26) \\
79.23(13.98)\end{array}$ & 0.21 & 0.650 & 0.00 & $0.54^{* * *}$ \\
\hline $\begin{array}{l}\text { Asthma-specific HrQoL } \\
\text { (DISABKIDS-AsM) }\end{array}$ & $\begin{array}{l}\text { Patient } \\
\text { Parent }\end{array}$ & $\begin{array}{l}65.44(19.90) \\
62.21(16.92)\end{array}$ & $\mathrm{I} .07$ & 0.302 & 0.01 & $0.36^{* * *}$ \\
\hline
\end{tabular}

${ }^{a}$ Intraclass correlation coefficients reference values: ICC $\leq .40=$ poor agreement, ICC between .41 and $.60=$ moderate agreement, ICC between $.6 \mathrm{I}$ and $.80=$ good agreement, $\mathrm{ICC} \geq .8 \mathrm{I}=$ excellent agreement (Landis \& Koch, 1977).

${ }^{* * *} p \leq .001 ;{ }^{* *} p \leq .01 ;{ }^{*} p \leq .05$, two-tailed.

\section{Discussion}

This is the first cross-cultural adaptation of an asthma-specific HrQoL questionnaire to the Portuguese pediatric context and the first study to examine the factorial structure of the DISABKIDS-AsM using CFA. Following the introduction of minor modifications (i.e. allowing the measurement error terms of the items related to physical activity to correlate), the correlated 
two-factor model presented good factorial validity; however, the low AVE by each factor suggested that a one-factor model would fit the Portuguese data better. The one-factor model had good fit to the patient-reported data and a nearly acceptable fit to the parent-reports. In addition, all items loaded significantly on the proposed global index of asthma-specific HrQoL, and the model was invariant across age groups (children vs. adolescents) and informants (patientreports vs. parent-reports). The psychometric qualities of reliability and validity of the Portuguese patient- and parent-reported versions of the DISABKIDS-AsM questionnaires as a global index of asthma-specific HrQoL resembled those described in the original study with an international sample from seven European countries (Baars et al., 2005).

The items included in the DISABKIDS asthma-specific module were originally derived from focus groups conducted with children and adolescents and primarily reflect the perspective of pediatric patients (Baars et al., 2005; The DISABKIDS Group Europe, 2006). Concordantly, the analytical strategy used in our study valued the patient-reported data to adjust the factorial model of the questionnaire, and subsequently the resulting model was tested for parentreported data. Although consistent with the World Health Organization recommendations for pediatric quality of life assessment (WHO, 1993), the child-centered approach may explain the poorer goodness-of-fit indexes for the parent-reported version of the instrument. These results, which were similar to those found in the psychometric studies of the chronic-generic module (Carona, Silva, Moreira, Canavarro, \& Bullinger, 20I4; Muehlan, 20I0), should not constitute an obstacle to the use of parent-reports as proxies, but instead imply that HrQoL assessment should employ patients' self-reports whenever possible.

The DISABKIDS-AsM questionnaires presented good reliability, confirming that their II items consistently reflect the latent construct of asthma-specific HrQoL, either assessed by children/adolescents or parents. Regarding convergent validity, the moderate and strong correlations with the generic and chronic-generic measures, respectively, provide additional evidence of the conceptual distinction between generic HrQoL and disease-specific impact (Wallander, Schmitt, \& Koot, 200I), even if they are hierarchically interrelated. The three HrQoL measures correlated differently with patients' and parents' perceptions of recency, frequency and severity of asthma symptoms, with stronger associations for the asthma-specific measure. Moreover, the chronic-generic and asthma-specific instruments have detected significant differences between asthma severity levels as assessed by physicians, in contrast to the generic measure. Thus, we advocate a multilevel assessment of HrQoL, including both generic domains and disease-specific impact, to ensure sensitivity to the differences in health status and to the specific healthcare needs of pediatric patients (Wiebe et al., 2003).

The absence of significant differences between informants on factor loadings and on item means, as well as on DISABKIDS-AsM total scores, attested to the strong agreement between 
patient- and parent-reports at the group level (Sneeuw et al., 2002). Nevertheless, at the individual level, the examination of ICC indicated poor to moderate levels of agreement. In addition, the parent-reports were strongly correlated with asthma symptoms, whereas patientreports were more sensitive in detecting differences between clinical severity levels. Taken together, these findings support the utility of a dyadic parent-child approach to HrQoL assessment (Bullinger et al., 2006), which may provide unique information about the impact of asthma on children/adolescents' psychosocial functioning and allow the identification of the socalled "hidden morbidities" (Varni, Burwinkle, \& Lane, 2005).

Although the original structure of the DISABKIDS-AsM consists of two correlated domains (Impact and Worry), these analyses suggested a one-dimensional measure. Nevertheless, these results do not preclude the use of the two domains for cross-cultural comparisons. This study is an example of a sequential approach to instrument development, in which a previously published measure is then translated and validated for a different language and culture (Schmidt \& Bullinger, 2003). These analyses should be replicated with samples from other countries in order to further examine whether a one-dimensional measure would better suit the asthma-specific HrQoL assessment in children and adolescents.

\section{Limitations and strengths}

The main limitation of this study was the non-probabilistic sample collection method and the heterogeneous distribution of children by asthma severity levels. The high percentage of participants with intermittent asthma, although consistent with the distribution of asthma severity levels that are typically observed in the Portuguese pediatric population (Gaspar, Almeida, \& Nunes, 2006), required the variable to be dichotomized and increased intragroup variability. In addition, the classification of asthma severity levels was based on expert opinion, rather than on physiological measures, which may disguise important differences in asthmaspecific HrQoL. Our study was also limited by its cross-sectional design, which precluded the examination of the test-retest reliability of the instrument and the ascertainment of a threshold for discrimination of clinically important changes in asthma-specific HrQoL. Although a score difference higher than a half a standard deviation has been proposed as a minimally important difference for HrQoL instruments (Norman, Sloan, \& Wyrwich, 2003), future longitudinal research with a higher number of children with severe asthma is required to further examine the sensitivity of the DISABKIDS-AsM questionnaires to developmental and clinical changes.

Despite these limitations, CFA is as a sophisticated and robust analytic procedure to ascertain construct reliability and factorial validity across age groups and informants. Our study was also strengthened by the multilevel assessment of HrQoL, including both generic, chronicgeneric and asthma-specific measures, and by the dyadic parent-child approach for data 
collection and analyses. The adopted multi-informant approach was also extended to the physicians' classification of asthma severity, thus enhancing the information collected from parents, which is likely to be biased by parental perceptions and expectations (Everhart \& Fiese, 2009). Therefore, we can conclude that the Portuguese patient- and parent-reported versions of the DISABKIDS-AsM questionnaires are reliable and valid measures for assessing the specificities of $\mathrm{HrQoL}$ in pediatric asthma patients.

\section{Conclusion}

In summary, this study validates the pertinence of using the Portuguese patient- and parent-reported versions of the DISABKIDS-AsM as a global index of asthma-specific HrQoL. An asthma-specific HrQoL instrument, which can be briefly completed by children/adolescents and by parents and that is sensitive to the clinical characteristics of asthma, is recommended as a primary health outcome for routine assessment in medical care and for research, particularly clinical trials and health policy/economy studies. The combined use of generic and specific modules allows clinicians and researchers to compare the HrQoL across children/adolescents with different health conditions or comorbidities without neglecting the sensitivity to the asthma-related impairments and healthcare needs. Moreover, the use of standard procedures to translate and validate the questionnaires ensures their cross-cultural equivalence and expands their utility in the international research context.

\section{References}

Anderson, J. B., Czosek, R. J., Knilans, T. K., \& Marino, B. S. (20I2). The effect of paediatric syncope on health-related quality of life. Cardiology in the Young, 22, 583-588. doi:10.1017/SI04795 I II2000I33

Austin, J. K., Smith, M. S., Risinger, M. W., \& McNelis, A. (1994). Childhood epilepsy and asthma: Comparison of quality of life. Epilepsia, 35, 608-6I5. doi:10.1III/j.1528II57.1994.tb0248I.x

Baars, R., Atherton, C., Koopman, H., Bullinger, M., Power, M., \& The DISABKIDS Group (2005). The European DISABKIDS project: Development of seven condition-specific modules to measure health related quality of life in children and adolescents. Health and Quality of Life Outcomes, 3, 70. doi:10.1 I86/1477-7525-3-70

Browne, M., \& Cudeck, R. (1993). Alternative ways of assessing model fit. In K. Bollen, \& J. Long (Eds.), Testing structural equation models (Pp. 136-162). Newbury Park, CA: Sage. 
Bullinger, M., Schmidt, S., Petersen, C., \& Ravens-Sieberer, U. (2006). Quality of life - Evaluation criteria for children with chronic conditions in medical care. Journal of Public Health, 14, 343-355. doi:10.1007/s 10389-006-0066-0

Carona, C., Silva, N., Moreira, H., Canavarro, M. C., \& Bullinger, M. (20I4). Does the small fit them all? The utility of Disabkids-10 Index for the assessment of pediatric health-related quality of life across age-groups, genders, and informants. Journal of Child Health Care. Advance online publication. doi:10.1/77//3674935/4522867

Chan, K. S., Mangione-Smith, R., Burwinkle, T. M., Rosen, M., \& Varni, J. W. (2005). The PedsQL: Reliability and validity of the short-form generic core scales and asthma module. Medical Care, 43, 256-265. doi:10.1097/00005650-200503000-00008

Dean, B. B., Calimlim, B. C., Sacco, P., Aguilar, D., Mayhut, R., \& Tinkelman, D. (20/0). Uncontrolled asthma: Assessing quality of life and productivity of children and their caregivers using a cross-sectional Internet-based survey. Health and Quality of Life Outcomes, 8, 96. doi:10.1 186/1477-7525-8-96

DeVellis, R. F. (2012). Scale development: Theory and applications (3rd ed.). Thousand Oaks, CA: Sage.

Dimitrov, D. M. (2010). Testing for factorial invariance in the context of construct validation. Measurement and Evaluation in Counseling and Development, 43, 121-149. doi: 10.1 1 77/07481756/0373459

Everhart, R. S., \& Fiese, B. H. (2009). Asthma severity and child quality of life in pediatric asthma: A systematic review. Patient Education and Counseling, 75, 162-168. doi:10.1016/j.pec.2008.10.001

Fornell, C., \& Larcker, D. F. (1981). Structural equation models with unobservable variables and measurement error: Algebra and statistics. Journal of Marketing Research, 18(3), 382-388.

Gaspar, A., Almeida, M., \& Nunes, C. (2006). Epidemiologia da asma grave [Epidemiology of severe asthma]. Revista Portuguesa de Imunoalergologia, I4(S2), 27-4I.

Global Initiative for Asthma. (2008). Global strategy for asthma management and prevention Updated 2008. Retrieved from http://www.ginasthma.org

Grootenhuis, M. A., Koopman, H. M., Verrips, E. G., Vogels, A. G., \& Last, B. F. (2007). Healthrelated quality of life problems of children aged 8-II years with a chronic disease. Developmental Neurorehabilitation, 10, 27-33. doi:10.1080/I368282060069/0I7

Guyatt, G. H. (1995). A taxonomy of health status instruments. The Journal of Rheumatology, 22(6), II88-II90.

Hair, J. F., Black, W. C., Babin, B. J., \& Anderson, R. E. (2010). Multivariate data analysis (7th ed.). New Jersey, NJ: Prentice Hall.

Hu, L., \& Bentler, P. M. (1999). Cutoff criteria for fit indexes in covariance structure analysis: Conventional criteria versus new alternatives. Structural Equation Modeling, 6, I-55. 
doi:10.1080/10705519909540I I8

Landis, J. R., \& Koch, G. G. (1977). The measurement of observer agreement for categorical data. Biometrics, 33(I), I59-174.

Moreira, H., Carona, C., Silva, N., Frontini, R., Bullinger, M., \& Canavarro, M. C. (20/3). Psychological and quality of life outcomes in pediatric populations: A parent-child perspective. Journal of Pediatrics, I63, I47I-I478. doi:10.1016/j.jpeds.2013.06.028

Muehlan, H. (2010). Developing the DCGM-I2: A short-form of the DISABKIDS condition-generic module assessing health related quality of life in children and adolescents with chronic conditions. Unpublished Doctoral Dissertation. University of Hamburg. Hamburg, Germany.

Norman, G. R., Sloan, J. A., \& Wyrwich, K. W. (2003). Interpretation of changes in health-related quality of life: The remarkable universality of half a standard deviation. Medical Care, $4 I(5), 582-592$.

Pearce, N., Aït-Khaled, N., Beasley, R., Mallol, J., Keil, U., Mitchell, E., Robertson, C., \& The ISAAC Phase Three Study Group. (2007). Worldwide trends in the prevalence of asthma symptoms: Phase III of the International Study of Asthma and Allergies in Childhood (ISAAC). Thorax, 62, 758-766. doi:10.1136/thx.2006.070169

Pinto, J. R. (20II). ISAAC (International Study of Asthma and Allergies in Childhood) 20 anos em Portugal [International study of asthma and allergies in childhood: 20 years in Portugal]. Acta Pediátrica Portuguesa, 42(5), 25-48.

Ravens-Sieberer, U., Erhart, M., Rajmil, L., Herdman, M., Auquier, P., Bruil, J., ... The European KIDSCREEN Group (2010). Reliability, construct and criterion validity of the KIDSCREEN-I0 score: A short measure for children and adolescents' well-being and health-related quality of life. Quality of Life Research, 19, I487-I500. doi:I0.1007/s I I I36$010-9706-5$

Ravens-Sieberer, U., Schmidt, S., Gosch, A., Erhart, M., Petersen, C., \& Bullinger, M. (2007). Measuring subjective health in children and adolescents: Results of the European KIDSCREEN/ DISABKIDS project. GMS Psycho Social Medicine, 4, 8.

Schmidt, S., \& Bullinger, M. (2003). Current issues in cross-cultural quality of life instrument development. Archives of Physical Medicine and Rehabilitation, 84, 29-34. doi:10.1053/apmr.2003.50244

Schmier, J. K., Manjunath, R., Halpern, M. T., Jones, M. L., Thompson, K., \& Diette, G. B. (2007). The impact of inadequately controlled asthma in urban children on quality of life and productivity. Annals of Allergy, Asthma \& Immunology, 98, 245-25I. doi:10.1016/SI08I1206(10)607/3-2

Silva, N., Carona, C., Crespo, C., \& Canavarro, M. C. (20I I). Avaliação da qualidade de vida em 
crianças e adolescentes com asma: Validação semântica e estudo piloto do DISABKIDS Módulo para a Asma [Assessing quality of life in children and adolescents with asthma: Semantic validation and pilot study of DISABKIDS - Asthma Module]. In A. S. Ferreira, A. Verhaeghe, D. R. Silva, L. S. Almeida, R. Lima, \& S. Fraga (Eds.), Actas do VIII Congresso Ibero-Americano de Avaliação Psicológical XV Conferência Internacional Avaliação Psicológica: Formas e Contextos (PP. |428-I44I). Lisbon: Sociedade Portuguesa de Psicologia.

Simões, M. R. (1994). Investigações no âmbito da aferição nacional do teste das Matrizes Progressivas de Raven [Raven's Progressive Matrices: Aferition studies]. Unpublished Doctoral Dissertation. Universidade de Coimbra. Coimbra, Portugal.

Sneeuw, K. C., Sprangers, M. A., \& Aaronson, N. K. (2002). The role of health care providers and significant others in evaluating the quality of life of patients with chronic disease. Journal of Clinical Epidemiology, 55(I I), I I30-I I 43.

The DISABKIDS Group Europe (2006). The DISABKIDS questionnaires: Quality of life questionnaires for children with chronic conditions - Handbook. Lengerich: Pabst Science Publishers.

Upton, P., Eiser, C., Cheung, I., Hutchings, H. A., Jenney, M., Maddocks, A., Russell, I. T., \& Williams, J. G. (2005). Measurement properties of the UK-English version of the Pediatric Quality of Life Inventory 4.0 (PedsQL) generic core scales. Health and Quality of Life Outcomes, 3, 22. doi:10.1 186/1477-7525-3-22

Varni, J. W., Burwinkle, T., \& Lane, M. (2005). Health-related quality of life measurement in pediatric clinical practice: An appraisal and precept for future research and application. Health and Quality of Life Outcomes, 3, 34. doi:10.1 I86/1477-7525-3-34

Varni, J. W., Limbers, C. A., \& Burwinkle, T. M. (2007). Impaired health-related quality of life in children and adolescents with chronic conditions: A comparative analysis of 10 disease clusters and 33 disease categories/severities utilizing the PedsQL ${ }^{\text {TM }} 4.0$ Generic Core Scales. Health and Quality of Life Outcomes, 5, 43. doi:10.1 I86/1477-7525-5-43

Wallander, J. L., Schmitt, M., \& Koot, H. M. (200I). Quality of life measurement in children and adolescents: Issues, instruments, and applications. Journal of Clinical Psychology, 57, 57I585. doi:10.1002/jclp. 1029

Wiebe, S., Guyatt, G., Weaver, B., Matijevic, S., \& Sidwell, C. (2003). Comparative responsiveness of generic and specific quality-of-life instruments. Journal of Clinical Epidemiology, 56, 52-60. doi:10.1016/\$0895-4356(02)00537-1

World Health Organization. (1993). Measurement of quality of life in children: Report of a WHOI IACAPAP working party. Geneva: Author.

World Medical Association. (2008). World medical association declaration of Helsinki: Ethical principles for medical research involving human subjects. Retrieved from http://www.wma.net/en/20activities/I0ethics/I0helsinki/ 